P-ISSN: 2541-6960; E-ISSN: 2549-8754

Yupa: Historical Studies Journal

Vol. 3 No. 1, 2019 (28-37)

http://jurnal.fkip.unmul.ac.id/index.php/yupa

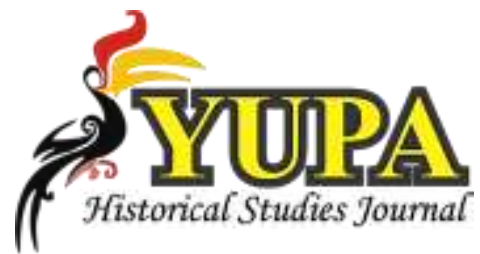

\title{
TNI-AD dan Kesatuan Aksi Mahasiswa Indonesia (KAMI) dalam Kelengseran Soekarno Tahun 1965-1968
}

\author{
Anju Nofarof Hasudungan \\ SMAN 1 Rupat, Riau, Indonesia \\ 1anjunofarof@gmail.com
}

\begin{tabular}{ccc}
\hline Received & Accepted & Published \\
$19 / 06 / 2020$ & $26 / 06 / 2020$ & $30 / 06 / 2020$ \\
\hline
\end{tabular}

\begin{abstract}
The events of the G30S 1965 became a major shock for the government of President Soekarno and even made Soekarno resign from his post. Apart from the impact of the G30 S 1965 incident, there were also actors involved in the action demanding that President Soekarno resign from his position. The purpose of this study is to describe how the Indonesian Army (TNI-AD) partnership and the Indonesian Students Action Unit (KAMI) in the political dynamics of 1965-1968. The method used is historical. Consists of heuristics, criticism (internal and external), interpretation, and historiography. The results showed that during the Three People's Demands (Tritura) action, KAMI was fully supported by TNI-AD. TNI-AD itself cannot bring criticism directly, let alone oppose the Supreme Commander. Therefore, KAMI was formed by TNI-AD to directly oppose President Soekarno. In the end, KAMI and TNI-AD leaders gained power after President Soekarno stepped down.
\end{abstract}

Keywords: Indonesian Army (TNI-AD), Indonesian Students Action Unit (KAMI), President Soekarno

\begin{abstract}
Abstrak Peristiwa G 30 S 1965 menjadi guncangan besar bagi pemerintah Presiden Soekarno bahkan membuat Soekarno lengser dari jabatannya. Tentunya, selain karena dampak dari peristiwa G30 S 1965 terdapat juga aktor-aktor yang terlibat dalam aksi menuntut Presiden Soekarno mundur dari jabatannya. Tujuan penelitian ini untuk mendeskripsikan bagaimana partnership TNI-AD dan Kesatuan Aksi Mahasiswa Indonesia (KAMI) dalam dinamika politik tahun 1965-1968. Metode yang digunakan adalah metode historis. Terdiri dari heuristik, kritik (intern dan ektern), interpretasi, dan historiografi. Hasil penelitian menunjukkan saat aksi Tiga Tuntutan Rakyat (Tritura), KAMI di dukung penuh oleh TNI-AD. Tentara sendiri tidak bisa melontarkan kritik secara langsung apalagi menentang Panglima Tertinggi. Karena itu, KAMI dibentuk oleh TNI-AD untuk secara langsung menentang Presiden Soekarno. Pada akhirnya, petinggi KAMI dan TNI-AD mendapatkan kekuasaan setelah Presiden Soekarno lengser.
\end{abstract}

Kata kunci: TNI-AD, Kesatuan Aksi Mahasiswa Indonesia (KAMI), Presiden Soekarno 


\section{PENDAHULUAN}

Tentara Indonesia tidak pernah membatasi dirinya hanya sebagai kekuatan militer. Masa revolusi tahun 1945 sampai 1949, tentara terlibat dalam perjuangan kemerdekaan dimana tindakan politik dan militer saling menjalin tidak terpisahkan. Sistem parlementer tahun 1957 yang membuat peran presiden dan wakil presiden menjadi lemah, jatuh bangunnya kabinet dan kegaduhan politik (sipil) membuat militer masuk dalam kancah politik. Kepala Staf Angkatan Darat Mayjend. Abdul Haris Nasution pada tahun 1958 merumuskan sebuah konsep yang bernama "jalan tengah" yang menetapkan bahwa pihak tentara tidak akan mencari kesempatan untuk mengambil alih pemerintahan, namun juga tidak akan bersikap acuh tak acuh terhadap politik.

Selain itu tentara juga menuntut hak mereka untuk tetap duduk dalam pemerintahan, lembaga perwakilan serta administrasi. Seminar pertama yang diselenggarakan pada bulan April 1965, tentara mencetuskan suatu doktrin yang menyatakan bahwa angkatan bersenjata memiliki peranan rangkap yaitu sebagai: kekuatan militer dan kekuatan sosial politik. Sebagai kekuatan sosial politik, kegiatan-kegiatan tentara meliputi bidang-bidang ideologi, politik, sosial, ekonomi, kebudayaan, dan keagamaan (Crouch, 1999). Persepsi tentara mengenai dirinya sebagai kekuatan politik berasal dari perbedaan yang kabur tentang fungsi militer dan fungsi politik dalam masa perang kemerdekaan melawan Belanda. Sifat perjuangan itu sendiri memiliki sifat politik sekaligus juga militer.

Militer merupakan kelompok kunci dalam dinamika politik di negara sedang berkembang pada umumnya, khususnya di negara dunia ketiga, seperti Indonesia. Secara umum, ada dua kelompok utama yang memandang faktor penyebab campur tangan militer dalam politik. Kelompok pertama melihat bahwa campur tangan itu lebih disebabkan oleh faktor internal. Dengan demikian, militer dianggap sebagai kelompok kelas kepentingan. Adapun kelompok kedua melihat hal itu diakibatkan oleh struktur politik dan institusional masyarakatnya. Penjelasan kelompok kedua ini, seperti yang pernah ditulis oleh Huntington, menandakan bahwa keterlibatan itu sebagai akibat rapuhnya struktur politik dan institusi masyarakat (Lembaga Ilmu Pengetahuan Indonesia, 1999).

Sebab lain yang menyebabkan kuatnya peranan Tentara Indonesia dalam politik adalah pola tingkah laku Panglima Besar Sudirman dimana menurut (A.H. Nasution, 1968:13 dalam Leni, 2013:33-34). Jenderal Soedirman berulangkali mengatakan bahwa tentara bukanlah alat mati, tetapi alat hidup. Disiplin tentara bukanlah disiplin kadafer, melainkan disiplin berjiwa. Sudirman juga tidak pernah menghindari persoalan politik negara, bergaul secara rapat dengan kaum politik, bahkan tidak jarang menjadi penengah dalam konflik antara pemerintah dan pihak oposisi. 
Gerakan mahasiswa selalu melihat persoalannya dari dua kondisi yang saling mempengaruhi. Pertama adalah kondisi obyektif, yakni melihat gerakan mahasiswa dalam kerangka persoalan yang lebih luas, misalnya struktur umur penduduk suatu negara serta sistem politik pada masa saat mahasiswa berkembang. Kedua adalah kondisi subjektif, yakni menilai variabel-variabel yang ruang lingkupnya langsung berhubungan dengan kepentingan para mahasiswa, keterbukaan pasaran tenaga kerja untuk lulusan universitas serta munculnya apa yang pada tahun 1960-an sudah ramai disebut sebagai suatu sub-kultur mahasiswa (Magenda, 1991).

Peneliti Indonesia asal Prancis, Francois Raillon, menyatakan bahwa Angkatan 66 anti partai politik, tapi pro Angkatan Darat. Peneliti buku Mahasiswa Indonesia dan Orde Baru itu menyatakan hubungan mereka dengan militer sifatnya seperti kakak-adik. Kerjasama dengan mahasiswa itu sangat berguna sekali bagi tentara, yang tidak bisa melontarkan kritik apalagi menentang atasannya sendiri, Presiden Soekarno. Karena itu, KAMI/KAPPI yang buka mulut. "Memang mereka dipakai atau barangkali diperalat oleh kakaknya yang militer itu," (Raillon, 1997). Hal tersebut menjadi latar belakang peneliti untuk mengkaji lebih lanjut mengenai bagaimana partnership TNI-AD dan Kesatuan Aksi Mahasiswa Indonesia (KAMI) dalam pusaran lengsernya Presiden Soekarno tahun 1965-1968.

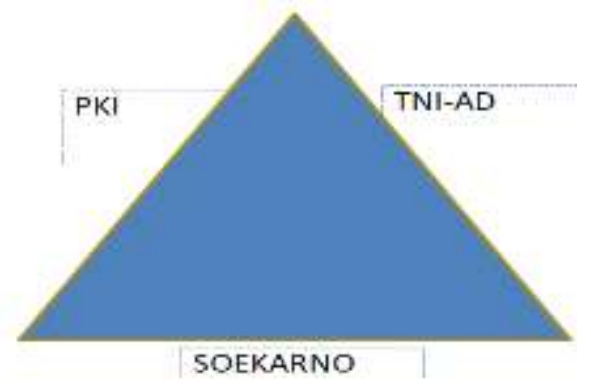

Gambar 1 Segitiga Emas Kekuasaan Orde Lama

\section{METODE}

Penelitian ini mengunakan metode sejarah yang terdiri dari heuristik, verifikasi, interpretasi dan historiografi. Heuristik adalah awal panggung untuk mengumpulkan semua data historis dari koneksi yang ada dengan tulisan ini (Ahmad, 2018). Pada tahapan ini, peneliti mencari dan mengumpulkan sumber yang berhubungan dengan topik yang akan dibahas dalam penelitian ini, yakni "TNI-AD dan KAMI dalam kelengseran Presiden Soekarno". Untuk memperoleh data-data tersebut, peneliti melakukan pengumpulan data pustaka, arsip-arsip atau dokumen di perpustakaan (Andrianto, 2018:2-3). 
Kemudian, peneliti melakukan Interpretasi terhadap fakta sejarah yang diperoleh dari arsip, buku-buku yang relevan dengan TNI-AD dan KAMI dalam kelengseran Soekarno. Interpretasi digunakan untuk mencari berbagai hal yang saling berkaitan antara satu fakta dengan fakta yang lain sehingga menjadi sebuah rangkain fakta yang logis dan mempunyai makna. Keterkaitan antara fakta sejarah tersebut yang nantinya akan memudahkan peneliti pada tahap selanjutnya yaitu tahap penulisan sejarah atau historiografi (Safitri, 2018:477).

Pada tahapan kritik, peneliti melakukan kritik sumber atau verifikasi dilakukan melalui dua cara yaitu kritik eksternal dan kritik internal: Kritik eksternal terdiri otentitas dan integritas. Kritik Internal terdiri menilai secara intrinsik sumber-sumber sejarah (Gunawan, 2015). Membuat perbandingan kesaksian dari berbagai sumber baik dari kalangan KAMI, TNI-AD dan maupun Soekarno. Menurut Renier (dalam Sudarno, 2018), sumber-sumber sejarah harus diperiksa dan diuji melalui eksternal kritik untuk mendapatkan data historis yang memiliki nilai validitas tinggi. Selanjutnya, data ditafsirkan bersama dengan konsep sejarah untuk membangun fakta. Kemudian, fakta-fakta dikorelasikan berdasarkan pada aturan kausalitas dalam sejarah. Jadi, semuanya menjadi kisah sejarah yang mendekati kebenaran dalam historiografi (penulisan sejarah).

\section{HASIL DAN PEMBAHASAN}

Nazar E. Nasution, Sekretaris jenderal (Sekjen) Pengurus Besar (PB) Himpunan Mahasiswa Islam (HMI) tahun 1966-1969 bahwa Kesatuan Aksi Mahasiswa Indonesia (KAMI) adalah tuntutan sejarah (Alfian, 2013). Pada tanggal 25 Oktober 1965, Mayor Jenderal Sjarif Thayeb, Menteri Perguruan Tinggi dan Ilmu Pengetahuan (PTIP) mengumpulkan para tokoh berbagai organisasi mahasiswa nonkomunis di rumahnya. Seperti, HMI, Perhimpunan Mahasiswa Katolik Republik Indonesia (PMKRI), Pergerakan Mahasiswa Islam Indonesia (PMII), Mahasiswa Pantjasila, Gerakan Mahasiswa Nasional Indonesia (GMNI), Gerakan Mahasiswa Kristen Indonesia (GMKI), Ikatan Mahasiswa Muhammadiyah (IMM), Serikat Mahasiswa Muslim Indonesia (SEMMI), Pelopor Mahasiswa Sosialis Indonesia (Pelmasi), Gerakan Mahasiswa Surabaya (GMS), Gerakan Mahasiswa Islam Indonesia (Germahi), Gerakan Mahasiswa Djakarta (GMD), Ikatan Mahasiswa Djakarta (Imada), Corpus Studisorum Bandungense (CSB), Masyarakat Mahasiswa Bogor (MMB), Ikatan Mahasiswa Bandung ((Imaba), dan Perhimpunan Mahasiswa Bandung (PMB) (HMI Online, 2018). KAMI mengibarkan ideologi antikomunis dan pembekuan organisasi-organisasi yang bernaung dibawahnya. Tuntutan ini, disebarluaskan ke jalan-jalan raya sehingga rakyat Jakarta bangkit melawan PKI dan Soekarno. Sebelumnya HMI memang diminta oleh Pak Sjarif Thayeb untuk tidak muncul diketua dengan alasan politis (Alfian, 2013). 
Munculnya gerakan mahasiswa dikarenakan kondisi ekonomi yang memprihatinkan, ketidakpuasan sosial, kebijakan luar negeri pemerintah yang tidak adil, ketidakpuasan terhadap penguasa, politik yang tidak demokratis, semua dipandang sebagai penyebab gerakan politik mahasiswa. Pada umumnya gerakan mahasiswa terjalin dengan keresahan masyarakat, kondisi sosial politik yang kritis pada waktu itu dan semakin memburuknya kondisi ekonomi memunculkan suatu angkatan baru yang mendapat kesempatan memainkan peranan (Rahmat \& Mukhammad Najib, 2001).

Pergerakan KAMI sebagai usaha untuk melengserkan pemerintahan Presiden Soekarno dilakukan dengan cara: pertama, kampanye anti Presiden Soekarno tampil secara terang-terangan pada tanggal 17 Agustus 1966. Pada hari itu Presiden Soekarno mengucapkan pidato berjudul "Jangan sekali-kali Melupakan Sejarah", yang terkenal dengan singkatan "Jas Merah". Pidato ini Presiden Soekarno mengkritik keputusan-keputusan yang diambil MPRS dan menganggap bahwa Surat Perintah 11 Maret tidaklah berarti pengalihan kekuasaan, tapi hanya pengalihan wewenang kepada Jenderal Soeharto untuk memelihara keamanan. Pidato yang dianggap sebagai provokasi ini melahirkan reaksi keras. Di Bandung, pidato ini dianggap sebagai sumber keributan, tanggal 19 Agustus 1966 ketika sekelompok orang bersenjata dan berseragam hitam yang dijuluki Gerombolan Liar Gestapu ASU menyerang Markas Besar KAMI dan KAPPI. Sehingga Julius Usman, Mahasiswa Universitas Katolik Parahiyangan, meninggal dunia dan lima belasan orang lainnya menderita luka-luka. Deklarasi KAMI diterbitkan: "Bung Karno tak dipercayai lagi, sabotase terhadap program Kabinet Ampera" (Raillon, 1989). Kedua, tindakan mogok kuliah dari tanggal 2 Februari hingga 10 Februari 1966, walaupun ada seruan dari Menteri Sjarif Thayeb untuk masuk kuliah, seruan tersebut tidak digubris atau memang bagian dari skenario antara KAMI dengan TNIAD. Ketiga, pada bulan September 1966 serangan terhadap Presiden Soekarno diteruskan dengan menggunakan fakta-fakta menurut KAMI yang didapat dari proses pengusutan Jusuf Muda Dalam, bekas Menteri Bank Sentral. Dituduh telah memberikan dana negara kepada Presiden untuk membiayai sejumlah aksi politiknya. Di awali pada 18 Maret 1966, sejumlah 15 orang Menteri ditangkap termasuk Waperdam I Soebandrio, Waperdam II Chaerul Saleh dan Jusuf Muda Dalam. Manuver ini mengejutkan Presiden Soekarno. Sebab, menteri-menteri yang ditangkap adalah orang-orang yang loyal tanpa reserve terhadap Presiden Soekarno. Ketiga, pada tanggal 30 Nopember 1966 KAPPI kembali melakukan demonstrasi ke DPR, dengan tuntutan yang sama seperti demonstrasi sebelumnya. Selanjutnya 9-12 Desember 1966 Sekitar 200 ribu mahasiswa mendesak agar Presiden Soekarno diadili. Keempat, pada tanggal 20 Desember 1966, KAMI, KAPPI, 
KAWI, KASI, KAMI Jaya, KAGI JAYA, serta Laskar Ampera Arif Rahman Hakim (ARH) menyampaikan fakta politik kepada MA mengenai keterlibatan Presiden Soekarno dalam G-30-S/PKI.

Berikut adalah bukti-bukti yang peneliti telusuri melalui berbagai macam sumber tulisan bahwa benar Kesatuan Aksi Mahasiswa Indonesia (KAMI) bekerjasama dengan elit TNI-AD, yakni: pertama, tokoh-tokoh Angkatan 66 mengakui mereka berkerjasama dengan ABRI saat itu untuk menggulingkan Presiden Soekarno dari kekuasaan. Berikut pengakuan Akbar Tanjung yang merupakan tokoh mahasiswa Angkatan 66, kepada Forum Keadilan: Akbar menyatakan, dia dan rekan-rekannya (menyebut diri sebagai Eksponen 66) setelah keuruntuhan Orde Lama tidak pernah melakukan usaha-usaha secara sadar untuk mendapatkan posisi tertentu atas nama Eksponen 66. "Kami tidak pernah merekayasa Eksponen 66 itu muncul sebagai pemimpin," ujarnya. Cuma, Akbar menegaskan, pengalaman dan semangat di tahun 1966 itulah yang dijadikan modal untuk ikut menyumbangkan pemikiran mereka untuk nusa dan bangsa. "Semangat itu juga kami pelihara dalam bentuk organisasi seperti Ikatan Keluarga Arief Rahman Hakim, atau yayasanyayasan," kata Akbar. Akbar juga tak menepis jika dianggap selama ini eksponen 66 terlalu dekat dengan ABRI.

Menurut Akbar, itu adalah realitas sejarah yang tak bisa dimungkiri lantaran, pada 1966, mereka sudah bergandeng tangan dengan ABRI sebagai kekuatan Orde Baru. Kedekatan itulah yang sampai kini terus mereka pelihara. "Di antara petinggi ABRI yang muda-muda itu, dulu ada juga yang aktivis 66" katanya (Majalah Forum Keadilan, 1997). Kedua, Angkatan 66 anti partai politik, tapi pro Angkatan Darat. Hubungan mereka dengan militer sifatnya seperti kakak-adik. Kerjasama dengan mahasiswa itu sangat berguna sekali bagi tentara, yang tak bisa melontarkan kritik apalagi menentang atasannya sendir: Presiden Soekarno. Karena itu, KAMI/KAPPI yang buka mulut. "Memang mereka dipakai atau barangkali diperalat oleh kakaknya yang militer itu," (Raillon, 1997). Ketiga, setelah Angkatan 66 (KAMI) dan ABRI (TNI-AD) berhasil menggulingkan Presiden Soekarno tidak sedikit dari tokoh-tokoh mahasiswa Angkatan 66 dan ABRI yang menduduki jabatan-jabatan penting baik Presiden, Wakil Presiden, Menteri, Pemimpin Perusahaan (BUMN), dan jabatan strategis lainnya, bahkan memfasilitasi banyak perusahaan asing untuk masuk ke negara Republik Indonesia seperti Caltex dan Freeport serta banyak lainnya yang dewasa ini dianggap telah menggeruk kekayaan alam Indonesia tanpa memberikan manfaat bagi bangsa Indonesia. Bahwa apa yang didapatkan oleh alumni-alumni KAMI seperti Menteri, Anggota DPR/MPR, HIPMI, dan membentuk KNPI merupakan sebuah investasi politik ketika bersama-sama menjatuhkan pemerintahan Presiden Soekarno. Aktivis-aktivisnya muncul sebagai orang yang sukses 
dibidangnya, baik politik maupun ekonomi, ungkap mantan Ketua Presidium KAMI Pusat Cosmas Batubara yang dulu juga pernah mendapat jatah dua kursi menteri pada masa Presiden Soeharto.

Rentetan peran yang diambil elit TNI-AD untuk menjatukan pemerintahan Presiden Soekarno sebagi berikut: pertama, setelah Men/Pangad Jenderal A.Yani gugur di tangan Gerakan 30 September, Pangkostrad Mayjend Soeharto mengambil alih kepemimpinan AD dengan restu Pangdam Jaya, Mayjend Umar Wirahadikusumah (Wakil Presiden Republik Indonesia keempat masa bakti 1983-1988). Setelah itu, Mayjend Soeharto menawarkan jabatan Men/Pangad ke Jenderal A.H. Nasution, tetapi ditolaknya. Dan pada akhirnya Presiden Soekarno mengambil alih jabatan tersebut dan menunjuk Mayjend Pranoto Reksosamudro sebagai caretaker (pengurus) Pangad. Tetapi Mayjend Soeharto tidak mengizinkan Mayjend Pranoto pergi ketika dipanggil menghadap Presiden. Sepeninggalan Letnan Jenderal Ahmad Yani yang gugur dan setelah Mayor Jenderal Soeharto berhasil menumpas komplotan Untung, target berikutnya membersihkan kekuasaan Presiden Soekarno. Penekanan Presiden untuk membubarkan Partai Komunis secara resmi, adalah jalan dipilihnya (Andrianto, 2018). Pada 6 Oktober 1965 Setelah Mayjend Soeharto menerima jabatan Men/Pangad secara sah, loyalis Presiden Soekarno yang sebelumnya ditunjuk menggantikan Jenderal Ahmad Yani. Yakni, Mayjend Pranoto diamankan di markas KOSTRAD dan kemudian ditahan. Tetapi, Presiden Soekarno akhirnya mengakui kepemimpian Mayjend Soeharto sebagai Men/Pangad yang berlaku surut sejak 1 Oktober 1965 (Keputusan No. 142/KOTI/1965 dalam Humaidi, 2008:43). Lagi, kewibawaan Presiden Soekarno mulai dipertanyakan. Pada 16 Oktober 1965 ketika Presiden Soekarno bahwa peristiwa pembunuhan para jenderal merupakan "Gelombang kecil dalam samudera revolusi". Pernyataan ini merupakan kemenangan moral TNIAD dan blunder bagi Presiden Soekarno (Ihsan, 2014:67).

Setelah Presiden Soekarno memecat Jenderal A.H. Nasution sebagai Menhankam/KSAB, mulai terjadi aksi-aksi unjuk rasa oleh KAMI dan KAPPI akibat tidak diwujudkan Tiga Tuntutan Rakyat (Tritura) yang salah satunya isinya ialah perombakan kabinet dari unsur-unsur komunis bukan menjadi pembersihan anti komunis. Aksi-aksi demonstrasi yang tidak terkendali tersebut berujung pada keluarnya Surat Perintah Sebelas Maret (Supersemar) 1966 atas usaha negosiasi dari perwira TNI-AD yakni Brigadir Jendral M. Jusuf, Brigadir Jendral Amirmachmud dan Brigadir Jendral Basuki Rahmat atas suruhan Mayjend Soeharto. Bahkan Presiden Soekarno dibawah tekanan dan bukanlah atas kemauan dan keinginannya (Adam, 2010). Pada 13-14 Maret 1966 akibat menyalahgunakan mandat Supersemar, Mayjend Soeharto ditegur oleh Presiden Soekarno. Hal ini dikarenakan Surat Keputusan (SK) Presiden/PANGTI ABRI/Mandataris MPRS/ PBR No 1/3/1966 tentang pembubaran Partai Komunis Indonesia (PKI). Maka, Bung Karno memerintahkan 
Wakil Perdana Menteri (Waperdam) II J Leimena untuk meminta pertanggungjawaban Soeharto sebagai pemegang Supersemar (Ginting, 2018).

Pada 16 Maret 1966 Presiden Soekarno kembali menjelaskan Supersemar. Ia menegaskan dirinya masih berkuasa penuh sebagai kepala eksekutif pemerintahan dan mandataris MPRS. Ia juga menegaskan, hanya dirinya yang berkuasa mengangkat menteri-menteri. Pada 18 Maret 1966, sejumlah 15 Menteri ditangkap atas desakan KAMI yang dieksekusi oleh TNI-AD dan diperintah Jenderal Soeharto (Baskara T, 2011). MPRS bersidang pada 20 Juni 1966, dan memilih A.H. Nasution sebagai ketua. MPRS kemudian mencabut gelar presiden seumur hidup dari Presiden Soekarno. Sepanjang bulan Juli 1966, Soeharto bertindak membentuk kabinet dan membersihkan orang-orang pendukung Presiden Soekarno. Presiden Soekarno menyampaikan secara tertulis pidato Pelengkap Nawaksara pada 12 Januari 1967. Ia mengatakan, peristiwa G30 S/PKI disebabkan oleh keblinger-nya pemimpin PKI, liicknya Nekolim, dan kenyataan adanya orang-orang aneh (Baskara T, 2011:91). Pada 17 Februari 1966, MPRS menolak pertanggungjawaban PelNawaksara Presiden Soekarno (Erlina, 2020:100). Karir politik Presiden Soekarno berada di ufuk senja, dan dia menghadapi ketidakpastian masa depan (Tim Lembaga Analisis Informasi, 2007). Dan akhirnya, hal-hal yang telah diusahakan oleh TNI-AD sejak tahun 1965 bekerjasama dengan Kesatuan Aksi Mahasiswa Indonesia (KAMI) berpuncak pada 27 Maret 1968, SK MPRS mengukuhkan Soeharto sebagai kepala negara (Museum Kepresidenan, 2020).

\section{KESIMPULAN}

Periode Indonesia tahun 1965-1968 adalah periode yang sangat pelik, tragedi, dan misteri karena itu terdapat banyak tafsir dalam memahaminya. Tulisan ini satu tafsir yang didasarkan pada sumber-sumber kepustakaan dan majalah mengenai partnership TNI-AD dan Kesatuan Aksi Mahasiswa Indonesia (KAMI) dalam dinamika politik tahun 1965-1968 yang berujung dengan lengsernya Presiden Soekarno. TNI-AD secara institusi tidak dibenarkan untuk menentang Panglima Tertinggi yakni presiden. Karena itu, kepentingan elit TNI-AD untuk mendapatkan kekuasaan memerlukan partner yakni, Kesatuan Aksi Mahasiswa Indonesia (KAMI).

Peran KAMI dalam usaha melesengerkan Presiden Soekarno seperti, kampanye anti Presiden Soekarno, aksi demonstrasi Tritura, mosi tidak percaya terhadap Presiden Soekarno. Menariknya, TNI-AD yang merupakan angkatan bersenjata tidak melakukan aksi-aksi yang mengunakan pesenjataan dalam upaya melesengserkan Presiden Soekarno. Tetapi, mengunakan metode kudeta merangkak (Creeping Coup d'etat) yakni, rangkaian kegiatan untuk mengambil kursi 
kepresidenan Soekarno secara bertahap sejak 1 Oktober 1965 sampai 1966 (keluarnya Supersemar) atau 1967 (pejabat presiden) atau 1968 (menjadi presiden). TNI-AD lebih cenderung memback up aksi-aksi KAMI dan melucuti kewibawaan Presiden Soekarno dengan menagkap dan menyidang loyalis-loyalis Preside Soekarno. Terakhir, melalui politik tingkat tinggi di MPRS maka Presiden Soekarno berhasil dilengserkan.

\section{REFERENSI}

Adam, A. W. (2010). Dua Aspek Supersemar. Lembaga Ilmu Pengetahuan Indonesia. http://lipi.go.id/berita/dua-aspek-supersemar/5372

Ahmad, N. (2018). Assimilating Indonesia Chinese Muslim in Makassar ( 1967-1997 ). Yupa: Historical Studies Journal, 2(1), 1-12. https://doi.org/10.3872/yupa.v2i1.91

Alfian, M. A. (2013). HMI (Himpunan Mahasiswa Islam) 1963-1966 Menegakkan Pancasila di Tengah Prahara. Penerbit Buku Kompas.

Andrianto, A. (2018). Kontroversi Keterlibatan Soeharto Dalam Penumpasan G30S/Pki 1965. Kalpataru: Jurnal Sejarah Dan Pembelajaran Sejarah, 2(2), 1. https://doi.org/10.31851/kalpataru.v2i2.1591

Baskara T, W. (2011). Suara di Balik Prahara; Berbagi Narasi tentang Tragedi '65. Galangpress.

Crouch, H. (1999). Militer dan Politik di Indonesia. Sinar Harapan.

Erlina, T. (2020). Peranan Kesatuan Aksi Mahasiswa Indonesia Dan Kesatuan Aksi Pelajar Indonesia Dalam Proses Peralihan Kepemimpinan Nasional. Jurnal Wahana Pendidikan, 7(2), 95-102. https://jurnal.unigal.ac.id/index.php/jwp

Ginting, S. (2018). Benarkah Soeharto Menyelewengkan Supersemar? Republika.Co.Id. https://republika.co.id/berita/selarung/suluh/18/03/11/p5f1ey282-benarkah-soehartomenyelewengkan-supersemar

Gunawan, I. (2015). PENELITIAN SEJARAH. http://fip.um.ac.id/wpcontent/uploads/2015/12/7.7_Penelitian-Sejarah.pdf

HMI Online. (2018). Peran (HMI) Himpunan Mahasiswa Islam (1965-1969). Medium.Com. https://medium.com/@hmi_online/peran-hmi-himpunan-mahasiswa-islam-1965-19697c8f34c87f58

Humaidi. (2008). Politik Militer Angkatan Udara Republik Indonesia Dalam Pemerintahan Sukarno 1962-1966 [Universitas Indonesia]. http://lib.ui.ac.id/file?file=digital/116747-T 24429-Politik militer-HA.pdf

Ihsan, M. (2014). POLITIK HUKUM DI INDONESIA DAN RELEVANSINYA DENGAN SIYÂSAH SYAR'IYYAH (STUDI KEBIJAKAN POLITIK HUKUM ORDE BARU TAHUN 1984-1998) [Program Pascasarjana Institut Agama Islam Negeri Sumatera Utara Medan]. http://repository.uinsu.ac.id/1670/1/tesis muhammad ihsan.pdf 
Lembaga Ilmu Pengetahuan Indonesia. (1999). Tentara Mendamba Mitra. PPW-LIPI \& Mizan Pustaka.

Leni, N. (2013). Keterlibatan militer dalam kancah politik di Indonesia. Jurnal Tapis: Jurnal Teropong Aspirasi Politik Islam, 9(1), 31-45. https://doi.org/10.24042/tps.v9i1.1574

Magenda, B. D. (1991). Gerakan Mahasiswa dan Hubungannya Dengan Sistem Politik: Suatu Tinjauan. LP3ES.

Majalah Forum Keadilan. (1997). Tokoh Indonesia Masa Depan. Majalah Forum Keadilan, 103.

Museum Kepresidenan. (2020). 27 Maret 1968 Soeharto Resmi sebagai Presiden RI Ke-2. Kementerian Pendidikan Dan Kebudayaan Direktorat Jenderal Kebudayaan. https://kebudayaan.kemdikbud.go.id/muspres/27-maret-1968-soeharto-resmi-sebagaipresiden-ri-ke-2/

Rahmat, A., \& Mukhammad Najib. (2001). Gerakan Perlawanan Dari Masjid Kampus. Purimedia.

Raillon, F. (1989). Politik dan Ideologi Mahasiswa Indonesia, Pembentukan dan Konsolidasi Orde Baru 1966-1974. LP3ES.

Raillon, F. (1997). Tokoh Indonesia Masa Depan Paradoks Cita-cita sebuah Angkatan. Majalah Forum Keadilan, 28-31.

Safitri, A. F. (2018). DAMPAK PENDIRIAN AGENTSCHAP VAN DE JAVASCHE BANK TE DJOKDJAKARTA TERHADAP KONDISI SOSIAL EKONOMI YOGYAKARTA TAHUN 1880-1940. Journal Student UNY, 475-489. http://journal.student.uny.ac.id/ojs/index.php/ilmusejarah/article/view/12508

Sudarno. (2018). the Colonization Trial Policy in Gedong Tataan, Lampung in 1905-1917. Paramita - Historical Studies Journal, 28(1), 1-12. https://doi.org/10.15294/paramita.v28i1.10916

Tim Lembaga Analisis Informasi. (2007). Kontroversi Supersemar dalam Transisi Kekuasaan Soekarno-Soeharto, edisi Revisi. Media Pressindo. 